\title{
Effect of coagulation bath temperature during preparation of PES hollow fiber supported liquid membrane for acetic acid removal
}

\author{
Sathiya Sanmugam ${ }^{1}$, Norlisa Harruddin ${ }^{1}$, Syed M. Saufi ${ }^{1}$ \\ ${ }^{1}$ Faculty of Chemical and Natural Resources Engineering, Universiti Malaysia Pahang, Lebuhraya Tun Razak, 26300 \\ Gambang, Pahang, Malaysia. Article Info: Submitted on March 20, 2017, Accepted on June 20, 2017.
}

\begin{abstract}
Acetic acid is a byproduct of acid hydrolysis of biomass during sugar recovery step in biofuel production. Acetic acid can inhibit the enzyme used during fermentation of sugar to the ethanol. Hollow fiber supported liquid membrane (SLM) was used in this study to remove acetic acid from aqueous solution. Liquid membrane was formulated using trioctylamine and 2-ethyl hexanol as a carrier and solvent, respectively. The hollow fiber membrane support was prepared from $15 \mathrm{wt} . \%$ polyethersulfone, $42.5 \mathrm{wt} . \%$ polyethyleneglycol 200 and 42.5 wt.\% dimethylacetamide. The effect of coagulation bath temperature (CBT) at $30^{\circ} \mathrm{C}, 40^{\circ} \mathrm{C}$ and $50^{\circ} \mathrm{C}$ during hollow fiber membrane spinning process was investigated. The porosity of the membrane increased as the CBT increased. The porosity of the membrane prepared using CBT of $30^{\circ} \mathrm{C}, 40^{\circ} \mathrm{C}$ and $50^{\circ} \mathrm{C}$ were $35.7 \%, 46.7 \%$ and $61.6 \%$, respectively. SLM process using hollow fiber membrane prepared at $50^{\circ} \mathrm{C}$ of coagulation bath was able to remove $52 \%$ of acetic acid from the aqueous solution.
\end{abstract}

Keywords: Supported liquid membrane; Biomass hydrolysate: hollow fiber membrane; Biofuel.

\section{Introduction}

Fossil fuels such as oil, coal and natural gas play an important role to produce fuels, electricity, chemicals and other useful products. However, the sign of depletion of fossil resources is undeniable these days. Lignocellulosic biomass has been pointed out to be one of the most promising alternative renewable resources to replace the fossil fuels. Pretreatment and hydrolysis of lignocellulosic biomass is necessary in order to recover the sugar compounds in biomass and converting them to bioethanol through fermentation process. However, these treatment processes induce the formation of inhibitor which directly restricts the microorganism activity during the fermentation process ${ }^{1}$. The fermentation inhibitors that are commonly found in lignocellulosic hydrolysates are aliphatic acid (acetic acid, formic and levulinic acid), furaldehydes, aromatic compounds and extractives ${ }^{2}$. Among them, it is found that acetic acid is the most serious inhibitor present in large amount in lignocellulosic biomass. It is necessary to remove acetic acid from the biomass hydrolysated before fermentation of xylose-rich sugars in order to increase the yield of the bioethanol.

Supported liquid membrane (SLM) is one of the membrane process that can selectively extracts the desired solute from an aqueous phase. In the SLM system, an organic liquid membrane phase is incubated within the pore of the membrane support. SLM process combines extraction and stripping in one single step unit operation. This process shows a great potential for the removal of acetic acid from aqueous solution due to their non-equilibrium mass transfer characteristics and very low inventory of organic solvent. Hollow fiber supported liquid membrane (HFSLM) is one of the SLM configuration which using hollow fiber membrane as the support. Hollow fiber membrane can provides high surface area per unit volume and gives high membrane flux. HFSLM have been used for extraction with various types solute using commercial hollow fiber membrane support. Swain et al. ${ }^{3}$ recovered cobalt and lithium from an aqueous solution using commercial Liqui-cel® hollow fiber module (Membrana-Charlotte, Celgard, LLC, USA) as the support. The reusability of the membrane module and zero discharge of effluent in the case of HFSLM can be a promising green technology over traditional dispersive solvent extraction ${ }^{3}$.Manna et al. ${ }^{4}$ separated catechin from tea leaves using HFSLM process and almost $57 \%$ of catechin was successfully recovered from the real extract with 70 minutes of extraction time. Wongkaew et al. ${ }^{5}$ used HFSLM to remove almost $96 \%$ of platinum (IV) from wastewater by using Aliquat 336 as a carrier.

Most of the HFSLM system used in the previous studies are using commercial hollow fiber as the membrane support. The properties of the commercial membrane is fixed and did not specifically fabricated for the HFSLM process. By fabricating suitable hollow 


\section{Chemical Engineering Research Bulletin 19(2017) 118-122}

fiber membrane support for SLM process, it is believed that the stability of the SLM can be improved and the removal performance of acetic acid can be enhanced. Therefore, in the current study, hollow fiber membrane support was fabricated through vapour induced phase separation (VIPS) method in order to investigate the effect of supported liquidon the HFSLM process. Polyethersulfone (PES) hollow fiber membrane was prepared at different coagulation bath temperature (CBT) and tested for removal of acetic acid from the aqueous solution.

\section{Materials and Methods}

\section{Chemicals}

Hollow fiber membrane was fabricated using PES (Radel@ A, Solvay, USA) as a base polymer, polyethylene glycol (PEG 200, Sigma Aldrich, MO) used as an additive and dimethylacetamide (DMAC, Sigma Adrich) as a solvent. 2-ethyl-1-hexanol (Merck, Darmstadt, Germany) was used as carrier by dissolving in tri-n-octylamine (TOA, Sigma) during formulation of liquid membrane phase. Acetic acid was purchased from Sigma and was used as the tested solute during SLM experiment.

\section{Preparation of dope polymer solution}

The dope solution was prepared based on the following mass composition: 15\% PES, 42.5\% DMAC, 42.5\% PEG 200. PES and PEG solid were dissolved in DMAC using IKA C-MAG HS 7 motorized stirrer until homogenous dope polymer solution was formed. The dope solution was left in room temperature overnight to remove air bubble formed during the mixing and ultrasonicated for at least 1 hour before used in spinning process.

\section{Hollow fiber membrane preparation}

PES hollow fiber membrane was prepared according to the VIPS process. In VIPS process, the hollow fiber emerged from the spinneret was passed through certain air gap distance at room humidity before fully immersed into the water coagualtion bath. Due to the air humidity, some solvent in the membrane had exchanged with the water in the air to initiate the phase separation. Detail condition of the spinning process was shown in Table 1 . Nitrogen gas at $0.1 \mathrm{MPa}$ was used to extrude the dope solution through spinneret. Tapwater was used as the bore fluid and coagulation bath medium. Spinning was done at three different CBT of $30^{\circ} \mathrm{C}, 40^{\circ} \mathrm{C}$ and $50^{\circ} \mathrm{C}$. The hollow fiber was immersed in water for 24 hours at room temperature before drying at open air.
Table 1: Spinning parameters in dry-wet spinning process.

\begin{tabular}{|l|c|}
\hline \multicolumn{1}{|c}{ Parameter } & Value \\
\hline Dope composition (wt. \%) & $15 \%$ PES/42.5\% \\
& PEG200/42.5\% DMAC \\
\hline Bore fluid & Water \\
\hline Bore fluid flowrate $(\mathrm{ml} / \mathrm{min})$ & $1-1.3$ \\
\hline Air gap distance $(\mathrm{cm})$ & 15 \\
\hline $\begin{array}{l}\text { External coagulant type } \\
\text { External coagulant } \\
\text { temperature }\end{array}$ & Water \\
\hline Take-up speed $(\mathrm{cm} / \mathrm{s})$ & Room temperature \\
\hline Spinneret dimension $(\mathrm{mm})$ & ID 2.0/OD 2.6 \\
\hline
\end{tabular}

\section{Membrane characterization}

Optical contact angle measurement system (CAM 101 Optical Contact Angle Meter, KSV Instruments) was used to determine the surface hydrophilicity of the membranes. Membrane porosity was calculated using equation $1^{6}$. The membrane was dried in a vacuum oven at $80{ }^{\circ} \mathrm{C}$ for 24 hours and weigh as $\mathrm{W}_{1}(\mathrm{~g})$. Then, the membrane was immersed in olive oil for 24 hours to ensure all the pores are filled with oil. The wet surfaces of the membrane were absorbed by using filter paper and weigh it as $\mathrm{W}_{2}(\mathrm{~g}) . \mathrm{V}\left(\mathrm{cm}^{3}\right)$ is the volume of the hollow fiber membrane and $\rho$ is the density of olive oil $0.8 \mathrm{~g} / \mathrm{cm}^{3}$.

$$
\varepsilon=\frac{W_{2}-W_{1}}{\rho V} \times 100 \%
$$

\section{Supported liquid membrane (SLM) system}

Five pieces of hollow fiber membrane was selected and glued using Loctite E30CL epoxy resin into $1 / 2$ inch stainless steel tube with $30 \mathrm{~cm}$ length as shown in Figure 1. Organic liquid membrane phase, $0.5 \mathrm{M}$ tri-noctylamine in 2-ethyl-1-hexanol, was pumped at 6 $\mathrm{ml} / \mathrm{min}$ to the bore side of the fiber for 1 hour during preparation of hollow fiber SLM. After one hour, the liquid membrane was pumped out from the bore side of the hollow fiber membrane.

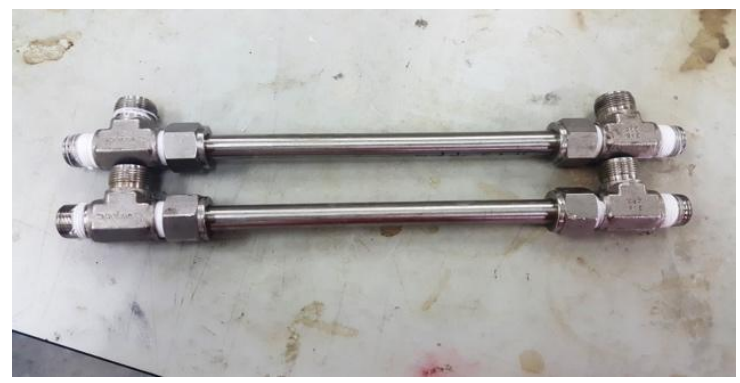

Figure 1: Hollow fiber membrane module. 


\section{Chemical Engineering Research Bulletin 19(2017) 118-122}

Figure 2 shows the SLM system used for acetic acid removal. $10 \mathrm{~g} / \mathrm{L}$ of acetic acid feed solution was flowed inside the hollow fiber membrane, meanwhile the $0.5 \mathrm{M} \mathrm{NaOH}$ stripping solution was flowed outside the hollow fiber membrane in countercurrent direction. The flowrate of feed and stripping phase were fixed to 75 and $50 \mathrm{ml} / \mathrm{min}$, respectively.

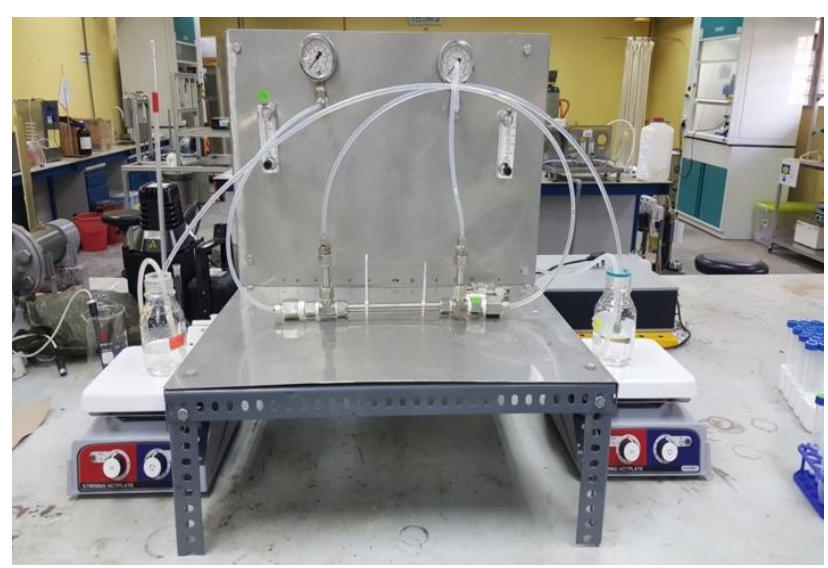

Figure 2: SLM system using hollow fiber membrane.

The performance of the membrane in the SLM process was evaluated using equation 2 based on the removal percentage of the acetic acid.

$$
\operatorname{Removal}(\%)=\frac{[A A]_{o}-[A A]_{f}}{[A A]_{o}} \times 100 \%
$$

Where, $[\mathrm{AA}]_{\mathrm{o}}$ and $[\mathrm{AA}]_{\mathrm{f}}$ are the initial and final concentration $(\mathrm{g} / \mathrm{L})$ of acetic acid in the feed phase, respectively. The concentration acetic acid was detected by Synergy Hydro C18 HPLC column (150 $\mathrm{mm} \times 4.6 \mathrm{~mm} \times 4 \mu \mathrm{m}$, Phenomenex) connected to Waters Acquity UPLC system. 0.02M potassium dihydrogen phosphate was used as mobile phase and acetic acid was detected by UV detector at $221 \mathrm{~nm}$ wavelength.

\section{Results and Discussion}

\section{Characterization of the membrane support}

The effect of CBT on the membrane porosity and contact angle was shown in Figure 3. Porosity of the membrane was increased linearly with the increased of the CBT. The increment of the porosity can be related with the increase of the macrovoid number and size in the membrane structure. The formation of the phase inversion membrane is controlled by phase equilibrium and diffusivities between the components in the dope solution and coagulation bath ${ }^{7}$. Immersion process of the dope polymer solution into the coagulation bath is a demixing process, where nuclei of a polymer-poor phase continue to grow with the continuation of the solvent and nonsolvent exchange until the polymer concentration at their limits becomes too high, and solidification occurs ${ }^{7}$. Thus, the rate of demixing process in the coagulation bath affects the membrane structure. Instantaneous demixing favors to the formation of more porous structure, whereas slow demixing often terminates to a denser structure ${ }^{8}$.

As the CBT increase, the solvent diffusion coefficient increases and system viscosity of polymer solution decreases ${ }^{9}$. High CBT enhance the mutual diffusivity between the solvent and nonsolvent during phase inversion and results in instantaneous demixing. A reduction in macrovoid size (and number) occurred at low CBT, since the process of macrovoid growth by coalescence of polymer-poor phase droplets would be more difficult ${ }^{9}$. As expected, the contact angle decreases with the increases of the porosity due to the increase of the CBT. The lowest contact angle would be obtained for the more porous membrane at CBT $50^{\circ} \mathrm{C}^{8,10}$. The low contact angle means high hydrophilicity (or low hydrophobicity) of the membrane surface. Although there have reduction trend in contact angle value, but the changes is not very significant at particular CBT.Similar finding was obtained by previous study when PVDF casting at CBT of 25 and $40^{\circ} \mathrm{C}$, the contact angle obtained were 88 and $89^{\circ 11}$. Therefore, it can be conclude that CBT does not influences on contact angles value.

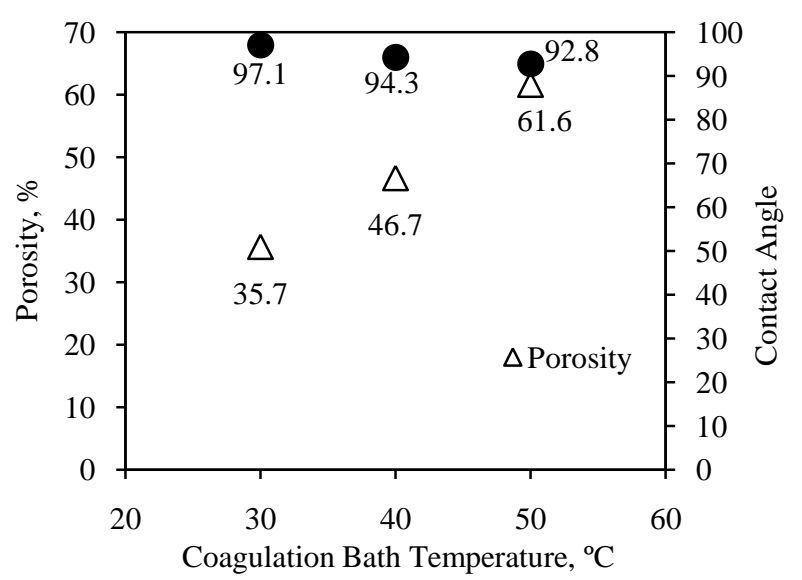

Figure 3: Effect of CBT on porosity and contact angle of hollow fiber membrane.

\section{Performance of hollow fiber SLM for acetic acid removal}

The percentage of acetic acid removal from aqueous solution using hollow fiber support prepared at different CBT in SLM experiment was shown in Figure 4 . The acetic acid removal percentage increased over the SLM operation time for all membranes. After 


\section{Chemical Engineering Research Bulletin 19(2017) 118-122}

eight hour of the SLM running time, the acetic acid removal percentage for the hollow fiber prepared at $30^{\circ} \mathrm{C}, 40^{\circ} \mathrm{C}$, and $50^{\circ} \mathrm{C}$ of CBT were $29.9 \%, 35.8 \%$, and $51.2 \%$, respectively. High acetic acid removal percentage using hollow fiber at high CBT can be related with the porosity increment of the support. High porosity hollow fiber support can contains more organic liquid membrane phase and hence increases the extraction capability. Although, the contact angle is slightly decreased as CBT increased, but the membranes still retain their hydrophobicity. Hydrophobic support is required for SLM support in order to avoid an organic liquid membrane phase leaks from the support.

\section{Conclusion}

The porosity of the PES hollow fiber membrane can be tailored by adjusting the CBT during the dry wet spinning process. High CBT create more porous membrane due to the instantaneous demixing of the solvent and nonsolvent during the phase separation. Highest membrane porosity was formed at CBT of $50^{\circ} \mathrm{C}$. In SLM experiment, almost $51.2 \%$ of acetic acid was able to removed from an aqueous solution of 10 $\mathrm{g} / \mathrm{L}$ acetic acid.

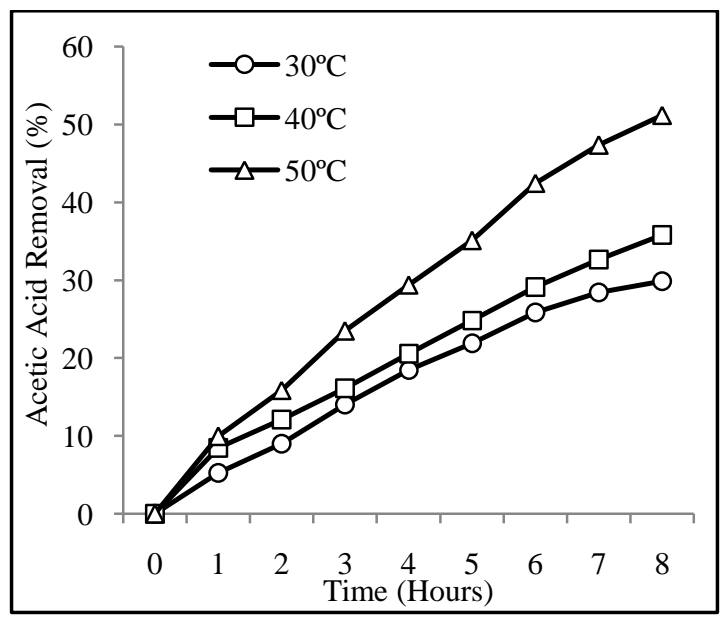

Figure 4: Effect of CBT during preparation of hollow fiber SLM for acetic acid removal from aqueous solution.

\section{Acknowledgement}

The authors were grateful for the research financial support by the Ministry of Higher Education Malaysia under the Fundamental Research Grant Scheme (FRGS RDU140144) and Universiti Malaysia Pahang under the Research University Grant Scheme (RDU140337).

\section{References}

1. H.J. Lee, W. S. Lim and J. W. Lee "Improvement of Ethanol Fermentation from Lignocellulosic Hydrolysates by the Removal of Inhibitors," Journal of Industrial and Engineering Chemistry,vol. 19, no. 6, pp. 2010-15,2013.

2. E. Palmqvist and H. H. Bärbel "Fermentation of Lignocellulosic Hydrolysates. II: Inhibitors and Mechanisms of Inhibition," Bioresource Technology,vol. 74, no. 1,pp.25-33, 2000.

3. B. Swain, C. Mishra. J. Jeong and H.S. Hong "Separation of $\mathrm{Co}(\mathrm{II})$ and $\mathrm{Li}(\mathrm{I})$ with Cyanex 272 Using Hollow Fiber Supported Liquid Membrane: A Comparison with Flat Sheet Supported Liquid Membrane and Dispersive Solvent Extraction Process," Chemical Engineering Journal,vol. 271, pp. 61-70, 2015.

4. M. S. Manna, P. Saha and A. K. Ghoshal"Separation of Medicinal Catechins from Tea Leaves (Camellia Sinensis) Extract Using Hollow Fiber Supported Liquid Membrane (HFSLM) Module," Journal of Membrane Science, vo. 471, pp.219-26. 2014.

5. K.Wongkaew, T. Wannachod,V. Mohdee, Pancharoen, Ura, A. Amornchai and A.W. Lothongkum"Mass Transfer Resistance and Response Surface Methodology for Separation of Platinum (IV) across Hollow Fiber Supported Liquid Membrane," Journal of Industrial and Engineering Chemistry, vol. 42, pp. 23-25, 2016.

6. N. Xu, J. Cao and Y. Lu "The Structure and Property Evaluation of Electrospun Porous Fibrous Membrane Based on the Copolymer of Styrene and Butyl Acrylate," Journal of Porous Materials, vol. 22, no. 6, pp. 1539-1548, 2015.

7. E. Saljoughi, M. Amirilargani and T. Mohammadi "Effect of PEG Additive and Coagulation Bath Temperature on the Morphology, Permeability and Thermal/Chemical Stability of Asymmetric CA Membranes," Desalination,vol. 262 no. 1-3, pp. 72-78. 2010.

8. J. Xu, Y. Tang, Y. Wang, B. Shan, L. Yu, and C. Gao "Effect of Coagulation Bath Conditions on the Morphology and Performance of PSf Membrane Blended with a Capsaicin-Mimic Copolymer," Journal of Membrane Science, vol 455,pp 121-30, 2014.

9. J. F.,Blanco, J. Sublet, Q. T. Nguyen and P.Schaetzel "Formation and Morphology Studies of Different Polysulfones-Based Membranes Made by Wet Phase Inversion Process," Journal of Membrane Science,vol. 283, no. 1-2, pp. 27-37, 2006.

10. M. Omidvar, S. M. Mousavi, M. Soltanieh and A. A. Safekordi, "Preparation and Characterization of Poly (Ethersulfone) Nanofiltration Membranes for Amoxicillin Removal from Contaminated Water," CBangladesh Uni. of Engg.\&Tech 121 


\section{Chemical Engineering Research Bulletin 19(2017) 118-122}

Journal of Environmental Health Science \& Engineering,vol. 12, no 1, pp,18,2014.

11. C. H. Loh and R. Wang, "Effects of Additives and Coagulant Temperature on Fabrication of High Performance PVDF/Pluronic F127 Blend Hollow Fiber Membranes via Nonsolvent Induced Phase Separation," Chinese Journal of Chemical Engineering,vol. 20, no. 1,pp,71-79,2012.

\section{Available online at http://www.banglajol.info/index.php/CERB}

